\title{
Using system dynamics to support a participatory assessment of resilience
}

\author{
Hugo Herrera $^{1}$ (i) $\cdot$ Birgit Kopainsky $^{1}$
}

Published online: 28 February 2020

(c) The Author(s) 2020

\begin{abstract}
Resilience has emerged as a buzzword among researchers and practitioners. However, despite its popularity, there has been little progress in moving it from a metaphor to applied projects. While case study research is rich with examples of systems that have proven to be resilient or are striving to develop resilience, the approaches for operationalising concepts described in the literature are still under development. This paper contributes to this development by incorporating system dynamics (SD) modelling within participatory approaches to resilience assessment. With this aim, we combined concepts and practices from the resilience literature with experiences, those documented in the literature and our own, applying system dynamics to resilience assessment. The proposed approach builds and complement other the literature by outlining a modelling process that is consistent with both the resilience literature and the SD modelling practices and providing a generic structure for designing interventions.
\end{abstract}

Keywords Resilience $\cdot$ Participation $\cdot$ Participatory assessment $\cdot$ Facilitated modelling

\section{Introduction}

Resilience can be defined the adaptive ability of a system to maintain functionality even when the system is has been affected by a disturbance (Gallopín 2006; Holling and Gunderson 2002; Folke 2006; Walker et al. 2002, 2004). In contrast to traditional risk management approaches that focus mainly on discrete strategies, resilience emphasises building adaptive capacity by providing the system with the conditions that allow it to reorganise itself into configurations that are more effective for dealing with disturbances (Biggs et al. 2012; Bosomworth et al. 2017; Folke 2006; Walker et al. 2004). Rather than seeking an optional solution, approaches for assessing resilience are concerned with understanding the system, fostering learning and implementing strategies that enhance flexibility and adaptation (Carpenter and Gunderson 2001; Davoudi et al. 2013 2012; Hawes and

Hugo Herrera

hugojhdl@gmail.com; hugo.leon@student.uib.no

Birgit Kopainsky

birgit.kopainsky@uib.no

1 Department of Geography, System Dynamics Group, University of Bergen, Fosswinckelsgate 6, 5007 Bergen, Norway
Reed 2006). This paper contributes to the development of operational approaches for the assessment of resilience by presenting an approach that incorporates system dynamics (SD) modelling with the participatory approach proposed by Walker and Salt (2012).

Evidence from decades of using participatory system dynamics (SD), also known in the literature as group model building (GMB) (Andersen et al. 2007), and our own experience using GMB to address complex problems, suggests that SD conceptual diagrams and formal simulation models could be helpful tools for the assessment of resilience. SD is a modelling methodology focused on understanding the circular relationships (feedback loops) driving the outcomes of a system (Richardson 2011). SD focuses on endogenous behaviour, making this approach an excellent candidate for learning about the structure of a system. GMB interventions focus on constructing causal loop diagrams (CLD) that are used as boundary objects (Black 2013) to facilitate discussion and knowledge creation (Zagonel 2002, 2004). CLDs are, in many cases, used as the basis for constructing mathematical models that can support the discussion with simulated trends. The purpose of the discussion is not to predict behaviour but to gain an understanding about "what happens if...'. 
There are several examples showcasing how SD can be used for resilience assessment and the insights and benefits it can yield (see Table 1). Some of these differences are practical. For instance, some authors only use SD for formulating causal loop diagrams, others keep developing simulation models and use them to explore scenarios (see Table 1). Similarly, the methodology used to build the model differs among cases with some authors using participatory settings and GMB for developing their models.

There are also differences regarding what is understood by resilience and how resilience is operationalised. For instance, some cases studies focused on performance of outcomes and functions (e.g. Ha and Duong 2018; Herrera 2018; Brzezina et al. 2016) while other cases focused on whether the present system configuration will remain despite major disturbances (e.g. Feofilovs et al. 2019; Machado et al. 2019).

The literature review shows that there is not a common approach for applying for applying SD to resilience assessment. The drawback of lacking such approach makes it difficult to compare and combine different case studies. Moreover, the conceptual looseness creates a disconnection between those applying SD and the wider community of practitioners undertaking resilience assessments. In this paper, we contribute to close these gaps by combining experiences documented in the literature and scripts and methods commonly used in SD (Andersen et al. 2007; Sterman 2000) into an adapted version of the participatory process proposed by the Resilience Alliance (2010). We do this by linking the cases reported in the literature, our own experience and the recommendations presented by the Resilience Analysis (2010) for assessing resilience.

\section{A participatory system dynamics approach for resilience assessment}

Following the recommendations in the literature (e.g. Bond et al. 2015; Resilience Alliance 2010; Walker et al. 2002), we propose that the SD modelling process should be conducted in an iterative manner actively engaging stakeholders. We argue that the aim of the process is not to find an optimal solution or to produce the best system description but "about creating a process whereby the system description is constantly revisited, reiterated, and fed into adaptive management" (Walker and Salt 2012, p. 53). The proposed modelling process can be summarised in two iterative phases (see Fig. 1):

(a) Eliciting their knowledge about the system, goals, values and needs and

(b) Confronting the knowledge elicited with quantitative data (historical or simulated by the model).
These two phases can be split in the five general steps presented in Fig. 1 and briefly described in Table 2. Next, we describe these steps in more detail using our experience assessing food security resilience to climate change in Guatemala as an illustrative example. We focus our description on the process while presenting tangible and intangible outcomes only to a level of detail needed to understand the benefits and limitations of the process. We recognise that a detailed description and analysis of the case study can yield interesting insights about small-scale farming, food security and climate change adaptation. However, this detailed analysis is outside the scope of this paper.

\subsection{Step 1: problem structuring process (resilience of what? and resilience for whom?)}

The resilience assessment process starts by developing a conceptual model of the system that identifies the boundaries of the system of interest (Henly-Shepard et al. 2015; Resilience Alliance 2010; Walker et al. 2002; Binning et al. 2001). While many case studies applying SD to resilience assessment do so without direct engagement of the stakeholders, we argue that involving stakeholders in this stage is vital to account for different and potentially conflictive agendas and perspectives (Givens et al. 2018; Herrera 2017; Cote and Nightingale 2012; Cretney 2014).

Our study in Guatemala was conducted using GMB and performed with the cooperation and participation of local stakeholders (farmers, government representatives, and academics). In GMB settings, a conceptual model of the system often takes the form of a causal loop diagram (CLD) and remains open to adjustments along the whole process (Walker et al. 2002). Building a conceptual model has three aims, (a) to conceptualise the analysis regarding the resilience of what? (Walker et al. 2002), (b) to agree on a causal explanation - the dynamic hypothesis (Sterman 2000) —of the mechanisms supporting the resilience of the system outcomes, and (c) to produce a boundary object, a tangible representation of stakeholders' mental models.

In our case study, the construction of the CLD started with the facilitator asking the participants to discuss the reasons for the recent decrease (see Fig. 2) in food security measured by using the proxy of average kilocalories (kcal) consumed per person per day (Vhurumuku 2014). Next, these explanations were captured through variables in a flipchart visible to the whole group. Once there were sufficient variables in the flipchart, the stakeholders connected them using arrows to indicate cause and effect relationships.

At the end of the process, the CLD produced looked like the one shown in Fig. 3. The thick lines in the figure highlight the main feedback loops discussed during the workshop and squares were placed around the strategic resources identified by the participants. Additional examples of conceptual 


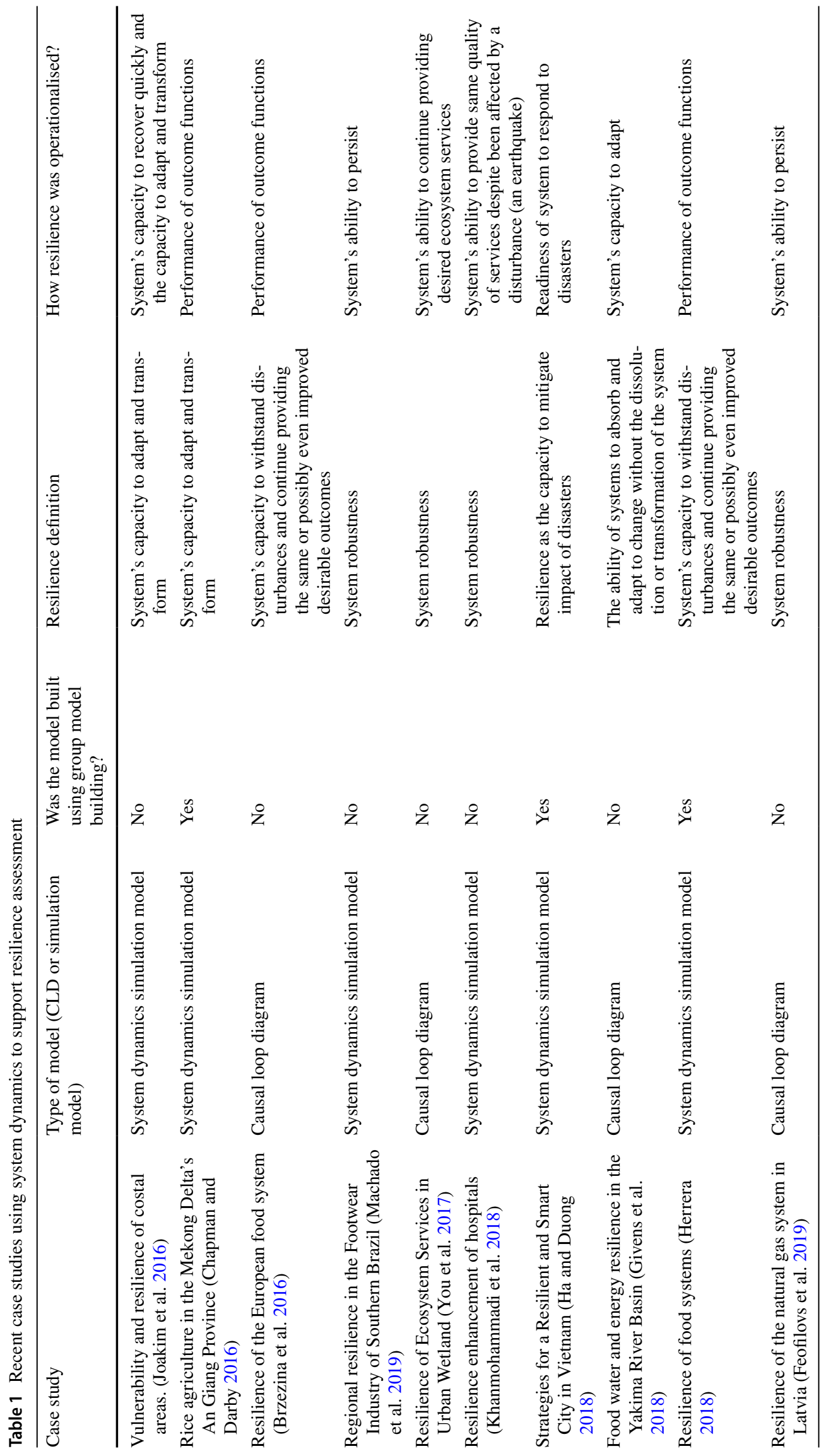


Fig. 1 A participatory modelling approach for the assessment of resilience

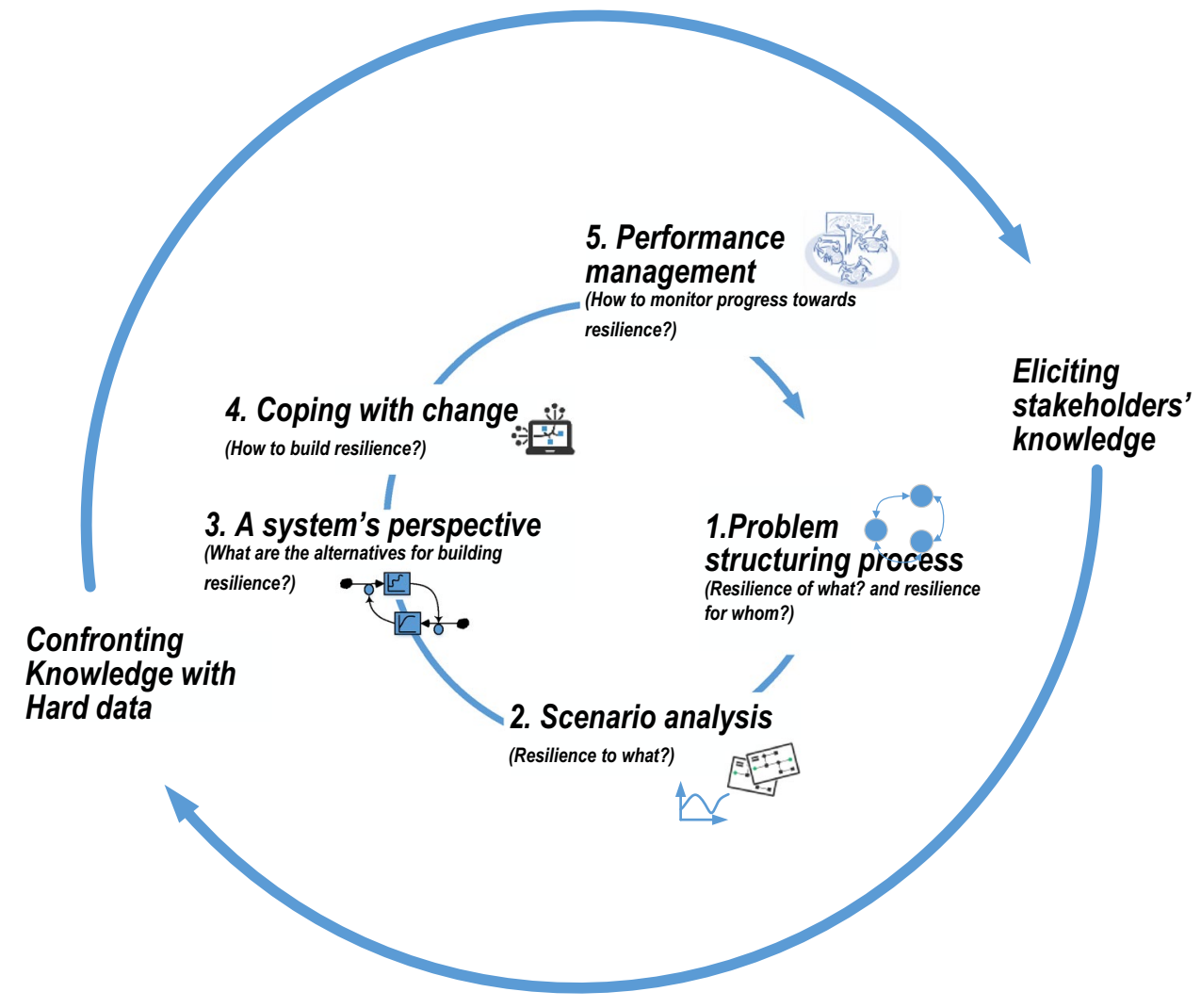

models can be found in Machado et al. (2019) and Brzezina et al. (2016).

\subsection{Step 2: scenario analysis (resilience to what?)}

Scenario analysis is a common factor in many case studies documented in the literature (e.g. Machado et al. 2019; Gray et al 2015; Mitchell et al. 2015) and also recommended by the Resilience Alliance (2010) practitioner's handbook. Exploring scenarios early in the modelling process helps practitioner to operationalise their answer to the question "resilience to what?" (Walker et al. 2002) by exploring disturbances that might affect the system in plausible alternatives futures (Mahmoud et al. 2009).

Drawing scenarios is also a way to elicit the expectations stakeholders might have about the system in general (König et al. 2012; Walker et al. 2002). The narratives describing each scenario are important because they provide a perspective of critical social factors shaping the development of the system, "such as values, behaviours and institutions" (Swart et al. 2004, p. 140).

A usual way to elicit scenarios in GMB workshops is to use graphs-over-time (Randers 1980). The graphs-over-time exercise can be used to elicit the expected behaviour of those parameters that affect the system behaviour over a certain time horizon (Andersen and Richardson 1997). An example of the graphs-over-time is shown in Fig. 4.
For example, in our case study, we used graphs-over-time to capture the behaviour of (a) external variables that might affect the system in a given time (disturbances) and (b) variables that might be affected by these disturbances. We did this in the first GMB workshop by asking participants to work in small groups identifying trends of the parameters that might affect the system and the effect of such trends on important outcomes of the system (e.g. food production, farm revenues, and so on)

Next, participants developed narratives for different scenarios by connecting graphs-over-time with arrows representing causality between variables (see Fig. 5). The diagrams produced and the narratives accompanying them describe potential developments for the system in a holistic way and helped stakeholder to consider a range of disturbances rather than a single stressor.

Figure 6 shows the final result of the exercise and the three scenarios developed by the stakeholders. Scenario 1 assumes that the biggest changes in the climate conditions have already happened (see Fig. 6) and the amount of rainfall will not continue to decrease in the mediumterm future. Scenario 2 describes a path in which rainfall will continue decreasing, thus increasing the severity of droughts in the region. Finally, Scenario 3 describes a future in which weather conditions are continually changing: severe droughts might be expected, followed by periods with abundant rainfall (probably even floods). These 

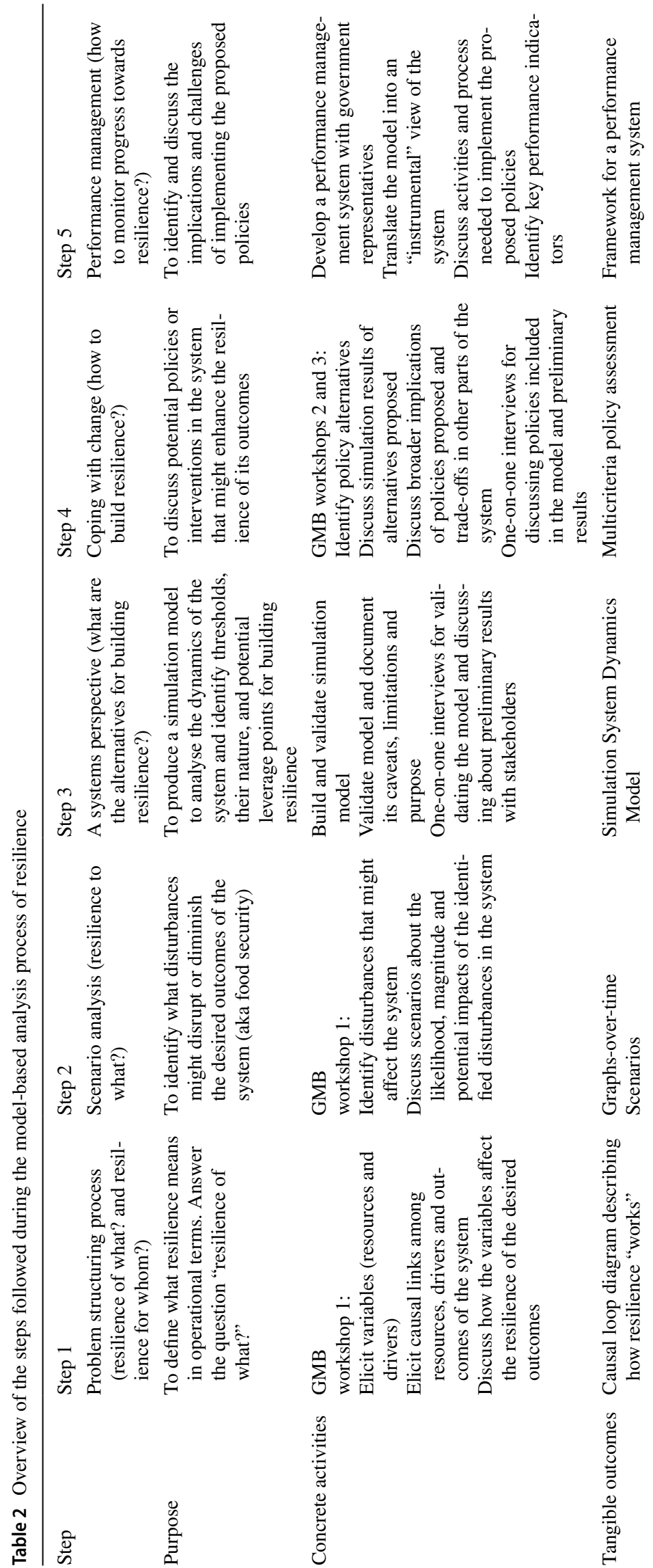

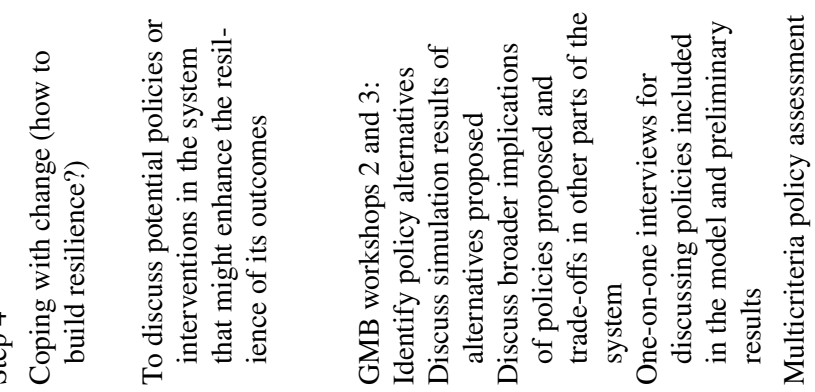
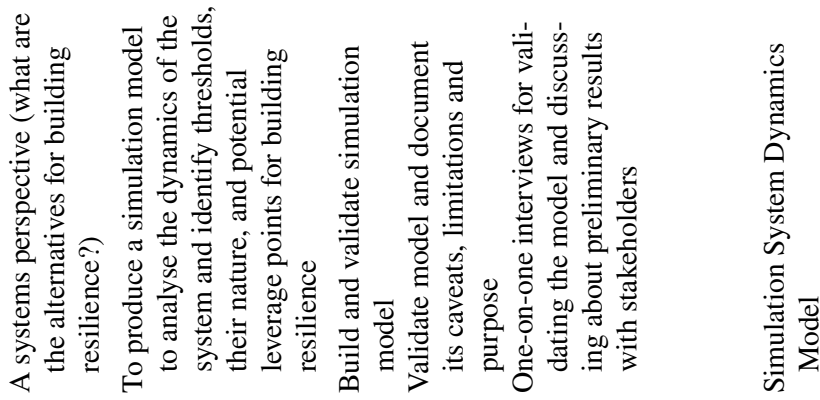

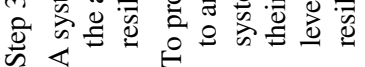
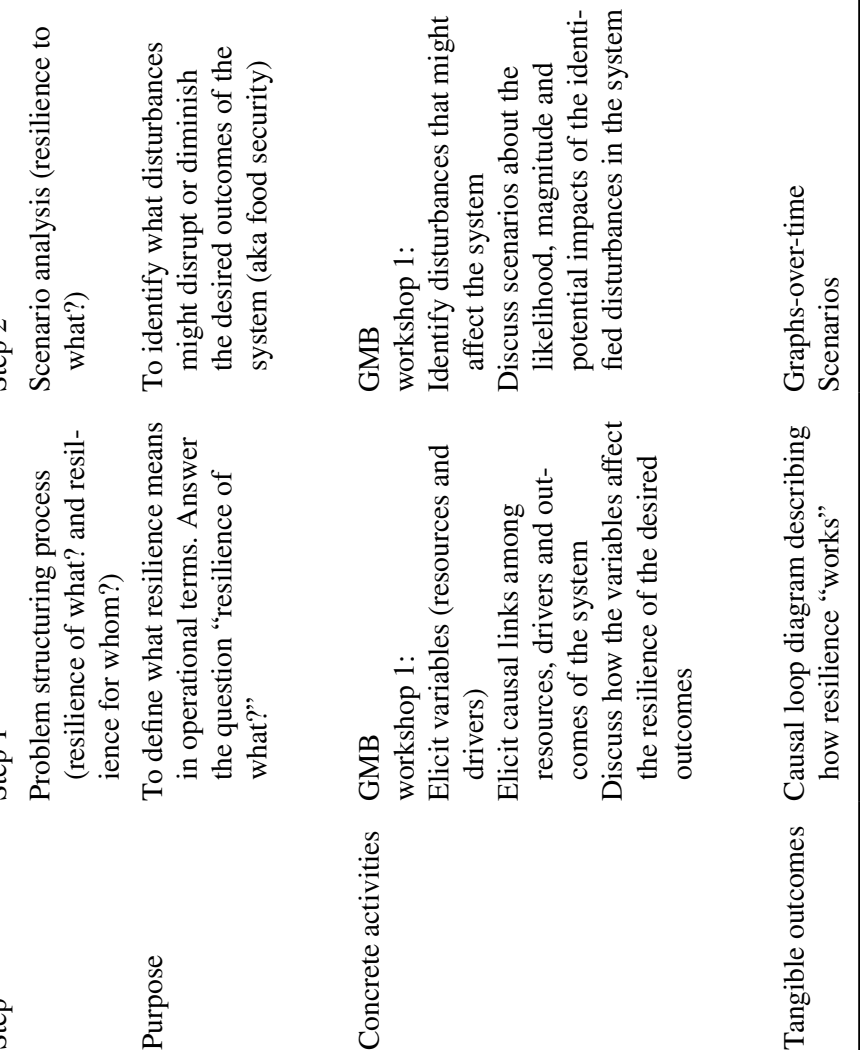
Fig. 2 Historical behaviour of kcal consumed per capita per day in Jutiapa, Guatemala. Source SESAN (2015)
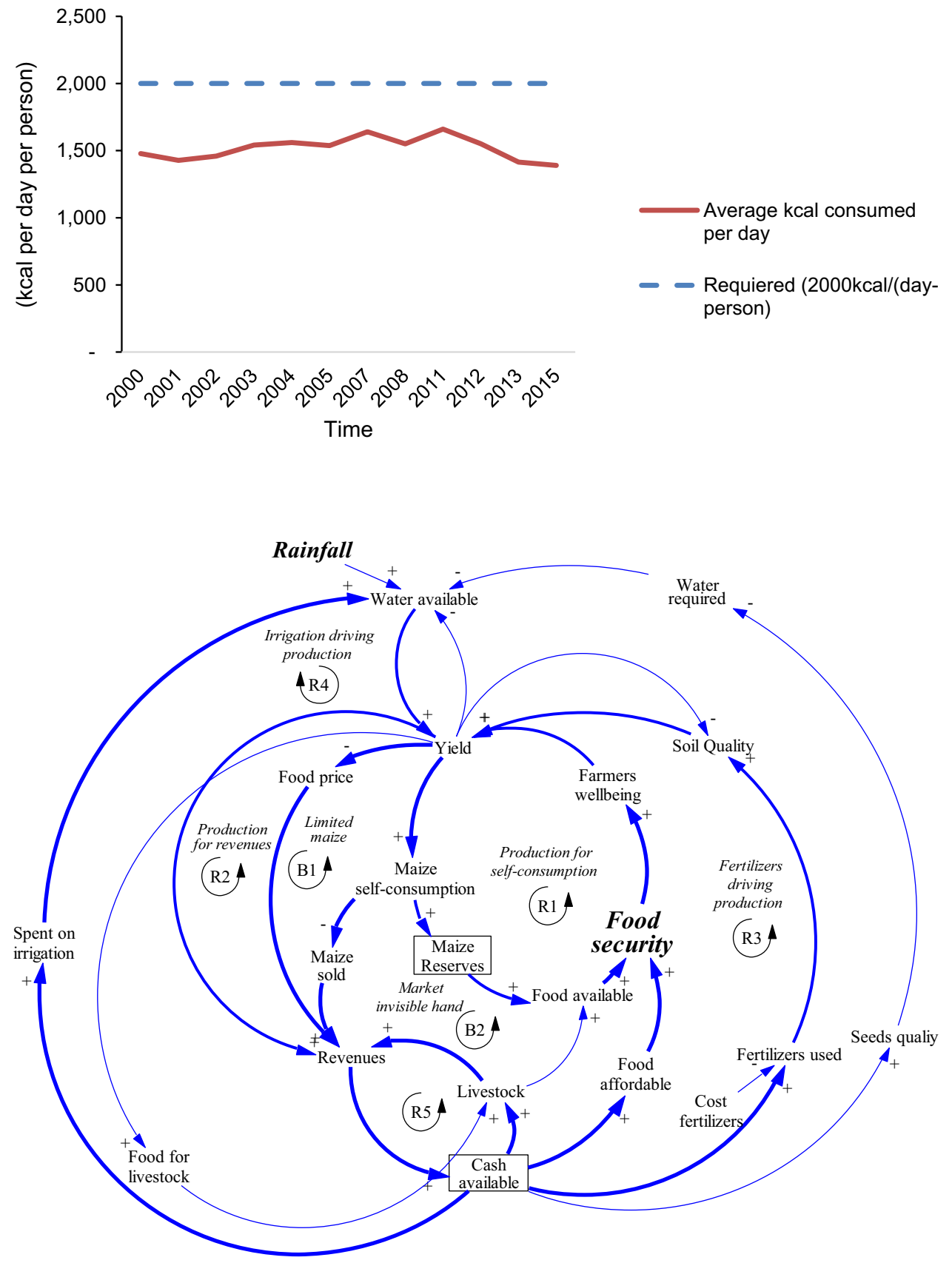

Fig. 3 Causal loop diagram created by delegates from stakeholders during the group model building workshop. Note: a plus (+) indicates that cause and effect move in the same direction, and a minus $(-)$ indicates that they move in opposite directions (Lane 2008). The polarity of the loops is identified by letters, an ' $R$ ' in the case of reinforcing or self-compounding loops and a ' $\mathrm{B}$ ' in the case of balancing or constraining ones

Fig. 4 a Picture and b stylised representation of one of the graphs-over-time produced by the participants during the workshop (a)

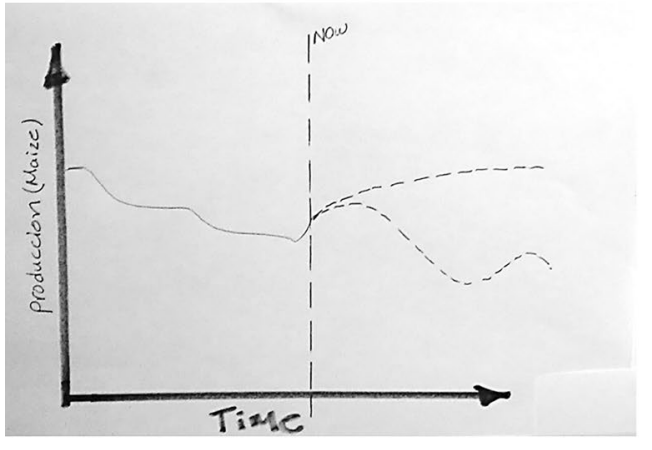

(b)

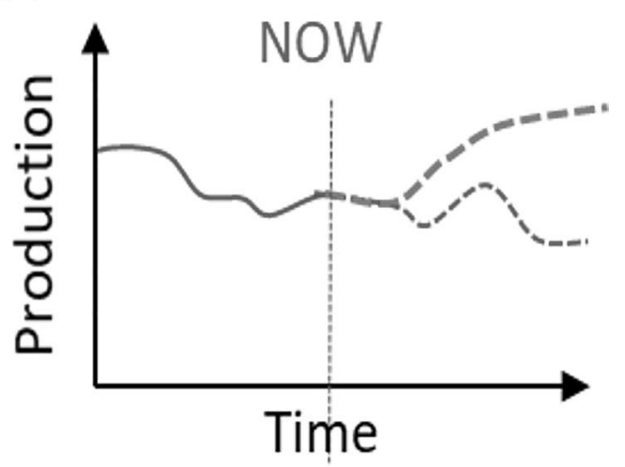



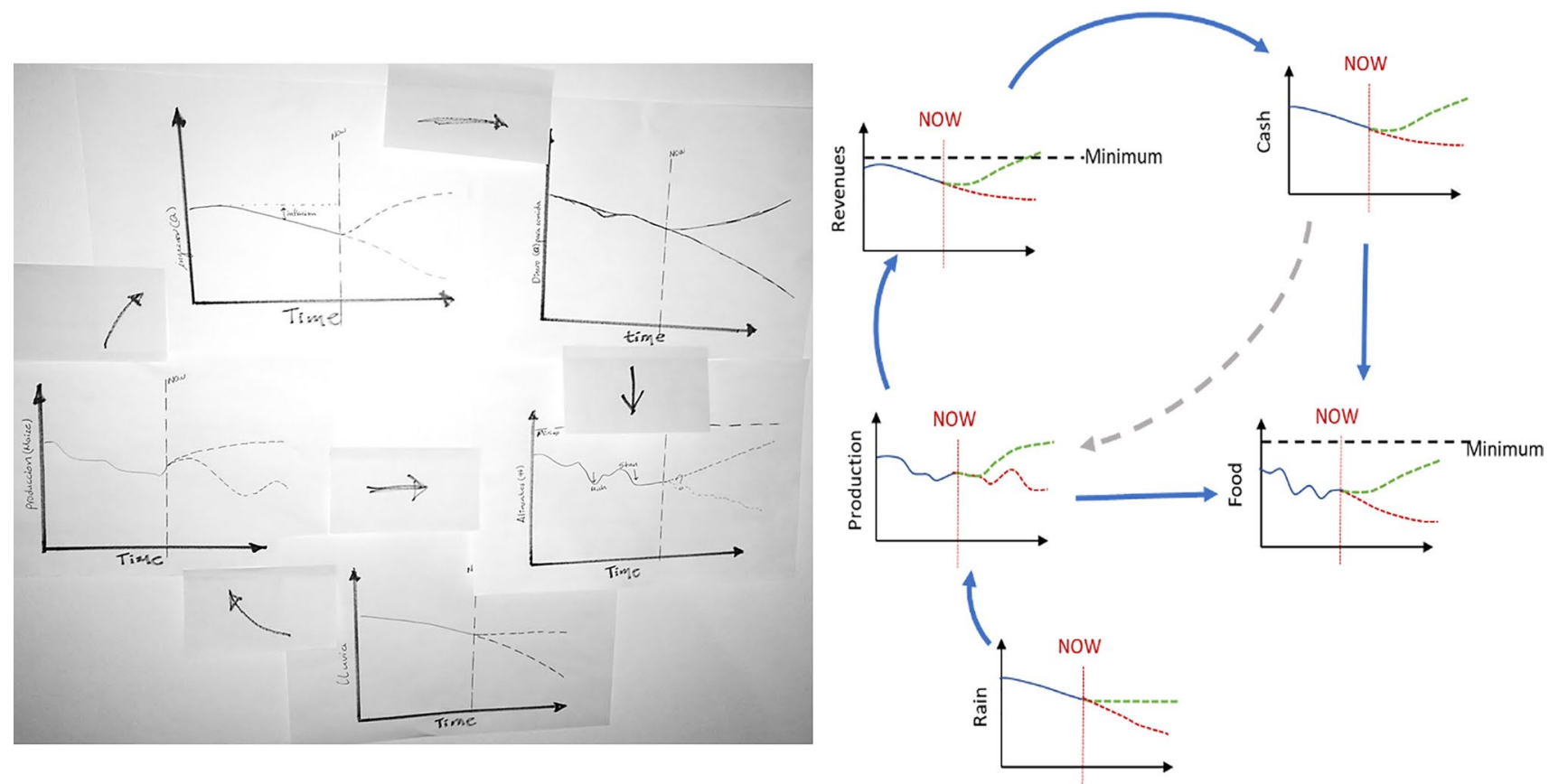

Fig. 5 Example of the graphs-over-time prepared by the participants

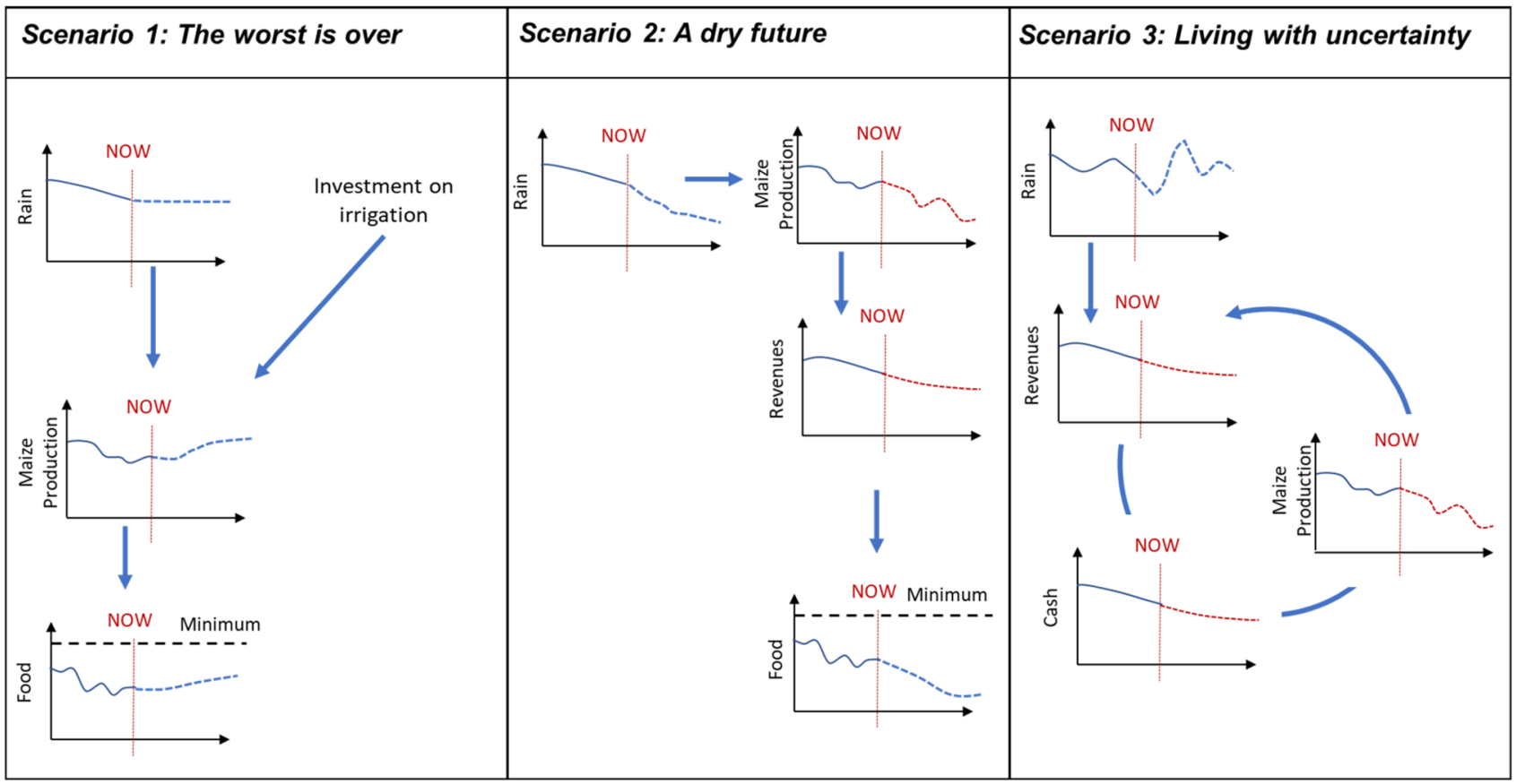

Fig. 6 Scenarios developed during the GMB workshop using graphs-over-time

scenarios were used later when the simulation model was used to quantify the system behaviour in a similar way to the scenario analysis described by Chapman and Darby (2016) and Machado et al. (2019). 


\subsection{Step 3: a systems perspective (what are the alternatives for building resilience?)}

The first two steps set up the boundaries of the system, capture the issues concerning stakeholders and develop a common language and understanding about what resilience means for this particular problem. Step 3 consists on using modelling methods to identify potential drivers of resilience and ways to intervene. The purpose of the model is to offer a simplified but realistic representation of the system and its behaviour for the scenarios considered.

The model might, as in this case, be built partially behind the scenes, but it needs to be based on stakeholders' perspectives and validated, fully understood and accepted by the stakeholders participating in the process. In our case, the model was based on the inputs captured in the CLD shown in Fig. 3 and was supported with statistical data and literature available. We devoted a considerable amount of time working with the stakeholders in one-to-one sessions to ensure the model was understood and that the relationships, data and principles included in the model were transparent to the stakeholders. The purpose of these sessions was to discuss the following:

(a) Variables containing assumptions without underlying empirical information.

(b) Simulation results produced and the feedback loops driving them.

(c) Results of sensitivity and stress tests performed in the model.

Once there is sufficient confidence in the model, the model can be used as an aid for identifying "thresholds, their nature, and what determines their positions along the driving variables" (Walker et al. 2002, p. 14). The model is used as a virtual laboratory for testing how changes in the system parameters affect the system behaviour and to identify points or areas for intervention (Sterman 2000). In our case, participants experimented with the model for about $45 \mathrm{~min}$ during the first half of the second GMB workshop (GMB workshop 2 in Table 2). The purpose of the exercise was to assess the effect of changing the value of certain parameters on variables that were thought to contribute to food security (e.g. maize price and food affordability).

While only few cases documented in literature describe experience using simulation models (Herrera 2018; Machado et al. 2019; Chapman and Darby 2016; Joakim et al. 2016), we argue that simulation models should be developed always that is feasible to do so. Having a simulation model offered an opportunity to stakeholders for challenging their own believes and understanding and to discuss in operational terms some mechanisms controlling the system. In our experience, counterintuitive results produced by the model sparked exciting discussions about the drivers of food security and the mechanisms influencing behaviour of the system that did not came up during the first workshop when the CLD was developed.

In our case study, the simulation results helped to change the perceptions stakeholders held about the mechanisms driving the behaviour of the system. At the beginning of the process, many of the stakeholders (some farmers included) believed that the revenues alone drove the system. This hypothesis was refined during the process as the other mechanisms in the system became more important to explain the simulated behaviour. The diagram in Fig. 7 illustrates one of these mechanisms driving resilience that became obvious during the analysis. When rainfall decreases, less water is available and this has a direct impact on the amount of maize produced. A reduction in the maize produced diminishes the returns farmers will get on their investment, reduces the cash available and diminishes both, the farmers' ability to buy food and to invest in future harvests.

For farmers, it is difficult to decide where to invest: in future harvests or in food they need for their own subsistence? On the one hand, investing in future harvests compromises their well-being and they have no certainty about how yields will be in the future. On the other hand, if farmers prioritise investing in food for subsistence, they will be cut off from their primary source of revenue in the mediumterm future.

The implications of this investment decision not only concern them but also the whole community. Maize produced locally is cheaper than maize coming from other communities and local households often prefer maize produced by neighbours. A temporary reduction in local production also affects them by temporarily reducing the supply and increasing consumer prices. Extreme events (like those anticipated in Scenario 3) also highlighted the importance of other strategic resources (e.g. maize reserves and livestock) as they will gain importance for maintaining resilience. If these two resources are well developed, they can be used during the dry years either as a source of food (if consumed by the farmers or exchanged for food) or as a source of cash (if sold).

\subsection{Step 4: copping with change (how to build resilience?)}

Within the concept of resilience, 'to cope with change' means to understand how the system reacts to external changes and the mechanisms that either stabilise them in a particular state (e.g. a clear lake) or push them towards different configurations (e.g. a murky lake) (Resilience Alliance 2010). Analysing the model and simulation results is 


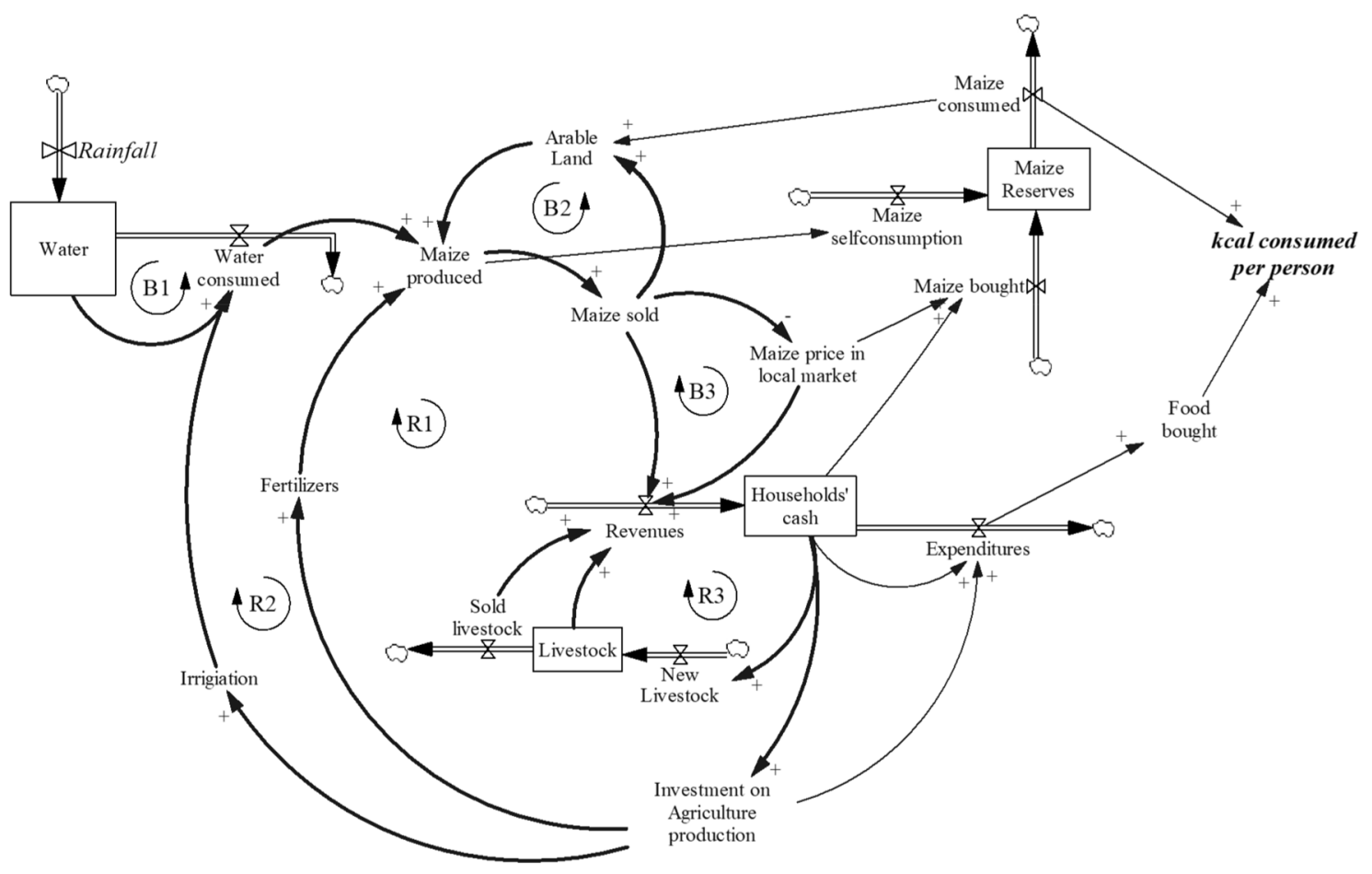

Fig. 7 Aggregated representation of the model

helpful alternative for identifying thresholds between system configurations and understanding the feedback loops influencing them. The insights gained during the Step 3 are used in the Step 4 to formulate strategies by identifying the mechanisms that enhance the ability of the system to reorganise and move within some configuration of acceptable states (Tompkins and Adger 2004; Walker et al. 2002).

While not all the case studies go as far as this step, there are some documented examples in the literature using SD to formulate potential strategies that enhance resilience. For instance, Ha and Duong (2018) combined Bayesian Belief Network model with SD to identify potential areas of intervention and held participatory workshop to formulate concrete strategies.

In our case study, we also used stakeholder input to develop potential policies by engaging with stakeholders in two consecutive GMB workshops (second half of GMB workshop 2 and GMB workshop 3 in Table 2). Namely, during the second half of the GMB workshop 2, after discussing the model results, we asked participants to work in small groups ( 3 participants) for approximately $30 \mathrm{~min}$, articulating what might be the best way to enhance the resilience of food security. Each group briefly presented their preferred strategy to the other stakeholders and the whole group selected a short list of potential strategies they wanted to test in the model (see Table 3).
In between the workshops two and three, the three strategies proposed were added to the model behind the scenes. The new iteration of the model was used to simulate the behaviour of the system for each scenario in Fig. 6. The simulation results were shared with all the participants and carefully discussed with each of them in one-to-one sessions before the next workshop (GMB workshop 3 in Table 2) took place. Finally, the model results showing the impact of the strategies proposed were discussed in the third GMB workshop. The discussion covered questions about the reasons behind particular behaviour as well as broader implications of each strategy (e.g. challenges of implementing some policies).

\subsection{Step 5: performance management (how to monitor progress towards resilience?)}

The final step of the resilience assessment is to translate the analysis into action (Resilience Alliance 2010). However, the question of how to translate insights from resilience into practice remains open halting implementation (Duit 2015; Glandon 2015). While having diagrams summarising findings and a simulation model produced with active stakeholder offer a good synthesis of the resilience assessment, the insights gained from the model still need refinement before being implementable. 
Table 3 Strategies for building resilience of food security to climate change

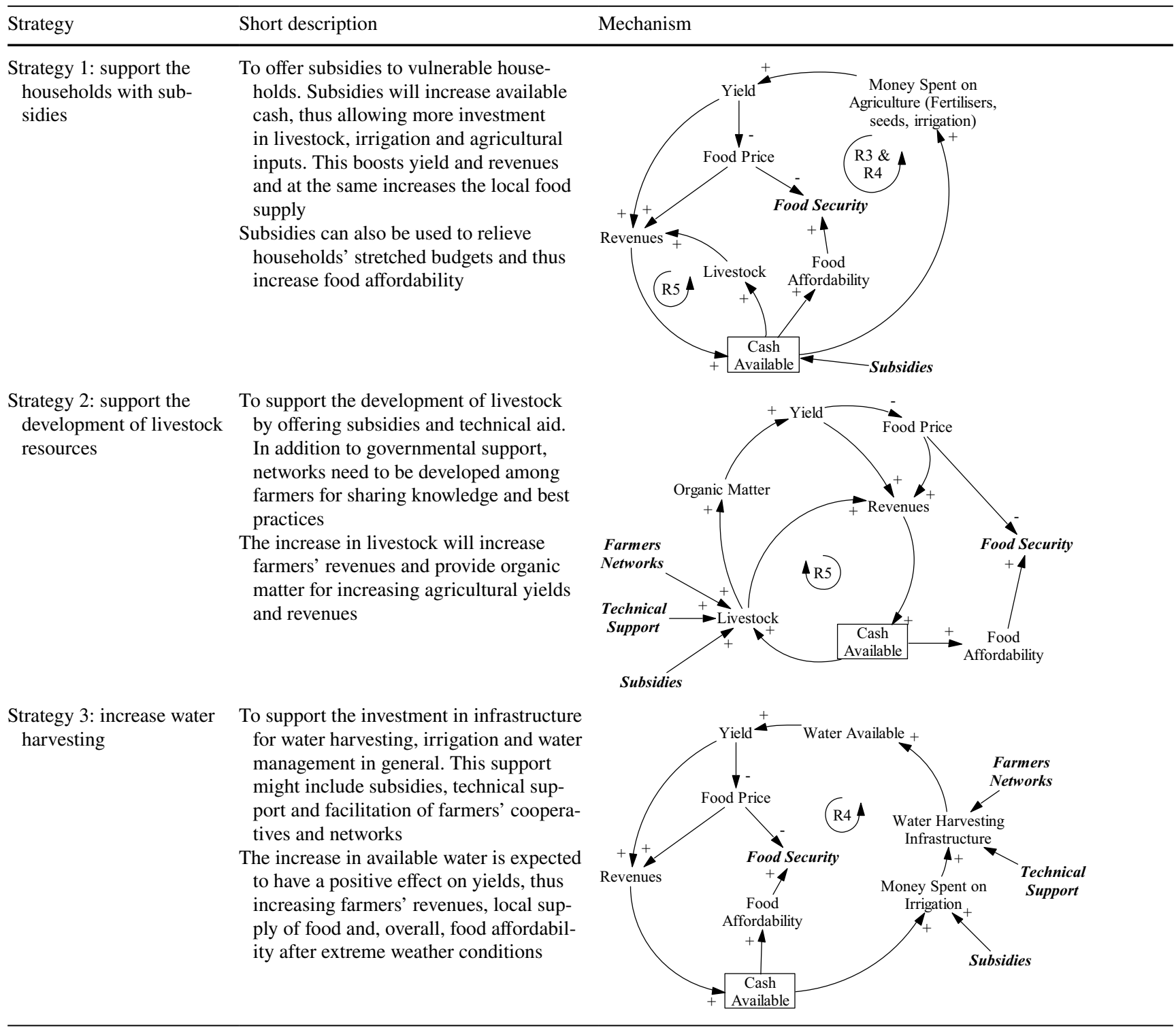

An alternative for linking SD model insights and implementation is to use dynamic performance management (DPM) diagrams (see Fig. 8). DPM is an approach for framing the causal mechanisms underlying performance that combines dynamic insights from SD and concepts from performance management (Bianchi 2016). The elements of a DPM diagram are summarised in Table 4. The DPM diagram combines these three elements to help stakeholders navigate from real processes (objective view) and feedback loop relationships (instrumental view) to high-level goals (subjective view) (Cosenz 2014).

It is important to highlight that the focus of the DPM diagram is on the strategy itself. For instance, the diagram contains key performance indicators (KPIs) for monitoring the progress and successful implementation of the strategy rather than progress towards resilience. Focusing on monitoring the strategy implementation solves some of the difficulties of trying to measure resilience and identifying thresholds for social-ecological variables. Details about how to design a DPM system that support resilience planning are given in Herrera (2018).

In this case, the DPM diagram was jointly developed by the authors and representatives of the central and local governments for the three strategies proposed (see Table 3). The development started in during the third workshop when we asked stakeholders to briefly enumerate the next steps needed to move from analysis to implementation. This list was later used for developing DPM 


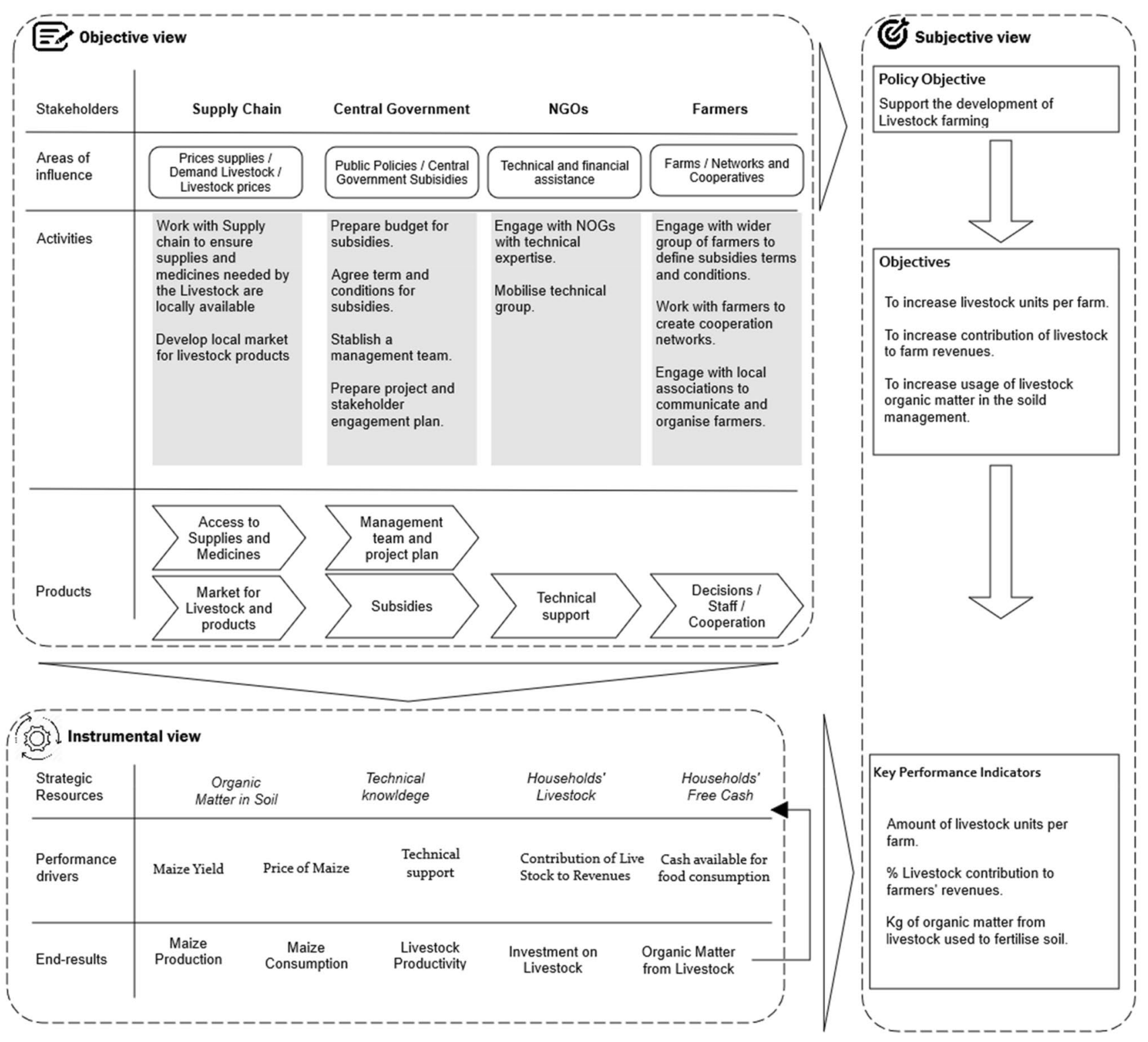

Fig. 8 Dynamic performance management diagram for strategy 2: support the development of livestock resources

Table 4 Elements of a dynamic performance management

\begin{tabular}{|c|c|c|}
\hline Element & Short description & Sub-elements \\
\hline Instrumental view & $\begin{array}{l}\text { Summary of the dynamic relationships between strategic resources } \\
\text { and performance outcomes }\end{array}$ & $\begin{array}{l}\text { Strategic resources: variables that accumulate over } \\
\text { time and influence the performance of the system } \\
\text { Performance drivers: parts of the system that can be } \\
\text { directly influenced through external intervention, } \\
\text { and } \\
\text { Performance outcomes: measurable outcomes that } \\
\text { reflect the status of the system }\end{array}$ \\
\hline Objective view & $\begin{array}{l}\text { Summary of the activities, processes and outputs needed to imple- } \\
\text { ment the strategy proposed in step } 4\end{array}$ & $\begin{array}{l}\text { Activities } \\
\text { Processes } \\
\text { Outputs }\end{array}$ \\
\hline Subjective view & $\begin{array}{l}\text { Summary of the final aims of the strategy and the main indicators of } \\
\text { success }\end{array}$ & $\begin{array}{l}\text { Strategic objectives } \\
\text { Key performance Indicators }\end{array}$ \\
\hline
\end{tabular}


diagrams combining work behind the scenes with one-toone meetings with representatives from the government. The topics addressed during these discussions were the following:

(1) What are the processes and activities needed to implement the strategy?

(2) What are the key products to be produced as part of the strategy?

(3) How could they monitor progress and performance?

(4) How will the proposed policies fit within the broader strategic context?

Figure 8 shows the DPM diagrams drafted for Strategy 2 as illustrative example. The figure shows, at a very high level, the important activities needed for implementing the policy, intermediate outcomes to be produced and the key performance indicators that can be used to monitor the policy performance.

We found that designing a DPM system helped government stakeholders to understand the resources needed and the feasible timescales for implementation. Moreover, the aforementioned process also allowed them to identify additional constraints and potential complications in the implementation. For instance, in the case of the Strategy 2 (incentivise livestock), providing appropriate veterinary assistance to all the farmers will be nearly impossible due logistical constraints and the isolation of the communities studied. The logistics needed pose a significant threat to the success of the policy, since livestock will need vaccines that have to be kept refrigerated and must be managed and transported appropriately. Without vaccines, the livestock will be susceptible to diseases and Strategy 2 will have limited success.

\section{Concluding remarks}

Resilience offers a very compelling framework to analyse the mechanisms a social-ecological system needs to adapt to climate change and other changes in the environment. However, the assessment of resilience beyond theoretical settings still lags behind, confuses researchers and practitioners and fails to gain traction in the policymaking world. The lessons learned from dealing with other wicked problems in social-ecological systems suggest that using SD models as boundary objects can help to tackle some of these challenges by offering a socially constructed operationalisation of resilience.

In this paper, we have proposed that SD models and simulations are helpful tools for the assessment of resilience. As shown in several case studies, using SD models unlocks new opportunities for the analysis of resilience and allows a transition to an operational discussion about outcomes, leverage points and resilience enablers. While the outcomes of the model are not predictive, the model helps to make sense of some assumptions, allows testing hypotheses and supports learning about the system. The simulation results can also be used in later stages to inform an economic assessment or a multicriteria analysis, thus supporting an evidence-based decision-making process. For example, after participating in the GMB workshops, stakeholders working in our case study commented:

(the model) Help us to see the complexity of the farmers' problem. It is not only about adding here or there, but about how to make it work (Delegate from Central Government)

Did not know how important the food reserves are for the farmers (Delegate from Local Government) Problem is complex, there are many ways to solve it, and we need to work together more (Delegate from Central Government)

However, to unlock the potential of SD in the resilience domain, the literature lacks a consistent approach that is simultaneously consistent with the resilience literature and practice and good SD practices. The approach proposed in this paper is a first step in the development of such approach system dynamics (SD) modelling in the assessment of resilience. This approach builds and complements other approaches and experiences described in the literature by outlining a modelling process that is consistent with both the resilience literature and the SD practices and providing a generic structure for designing replicable and comparable interventions.

Building resilience requires an iterative approach that allows stakeholders to learn from the system as much as to plan practical interventions. The approach we propose, as do others in the literature, covers this full cycle and sets up a process that helps stakeholders to navigate between abstract concepts of resilience and the practicalities of governing the system. In particular, introducing the DPM system as part of the process supports the development of concrete actions and processes that can help to build resilience. While the DPM is still at a high level, it works as a bridge between analysis and practice and offers a baseline for developing projects. This extra step towards implementation might be helpful tool when engaging with public officials and is likely to help to build confidence in the feasibility and viability of the strategies proposed.

Acknowledgments Open Access funding provided by University of Bergen. 


\section{Compliance with ethical standards}

Conflict of interest The authors declares that they have no competing interest.

Open Access This article is licensed under a Creative Commons Attribution 4.0 International License, which permits use, sharing, adaptation, distribution and reproduction in any medium or format, as long as you give appropriate credit to the original author(s) and the source, provide a link to the Creative Commons licence, and indicate if changes were made. The images or other third party material in this article are included in the article's Creative Commons licence, unless indicated otherwise in a credit line to the material. If material is not included in the article's Creative Commons licence and your intended use is not permitted by statutory regulation or exceeds the permitted use, you will need to obtain permission directly from the copyright holder. To view a copy of this licence, visit http://creativecommons.org/licenses/by/4.0/.

\section{References}

Andersen DF, Richardson GP (1997) Scripts for group model building. Syst Dyn Rev 13(2):107-1297

Andersen DF, Vennix JAM, Richardson GP, Rouwette EAJA (2007) Group model building: problem structuring, policy simulation and decision support. J Oper Res Soc 58(5):691-694

Bianchi C (2016) System dynamics for performance management 1 dynamic performance management. Springer, Cham

Biggs R, Schluter M, Biggs D, Bohensky EL, Burnsilver S, Cundill $\mathrm{G}$ et al (2012) Toward principles for enhancing the resilience of ecosystem services. Annu Rev Environ Resour 37:421-448

Binning CE, Cork SJ, Parry R, Shelton D (2001) Natural assets: an inventory of ecosystem goods and services in the Goulburn Broken Catchment. CSIRO, Canberra

Black LJ (2013) When visuals are boundary objects in system dynamics work. Syst Dyn Rev 29(2):70-86

Bond A, Morrison-Saunders A, Gunn JA, Pope J, Retief F (2015) Managing uncertainty, ambiguity and ignorance in impact assessment by embedding evolutionary resilience, participatory modelling and adaptive management. J Environ Manage 151:97-104

Bosomworth K, Leith P, Harwood A, Wallis PJ (2017) What's the problem in adaptation pathways planning? The potential of a diagnostic problem-structuring approach. Environ Sci Policy 76:23-28

Brzezina N, Kopainsky B, Mathijs E (2016) Can organic farming reduce vulnerabilities and enhance the resilience of the European food system? A critical assessment using system dynamics structural thinking tools. Sustainability 8(10):971

Carpenter SR, Gunderson L (2001) Coping with collapse: ecological and social dynamics in ecosystem management. Bioscience 51(6):451-457

Chapman A, Darby S (2016) Evaluating sustainable adaptation strategies for vulnerable mega-deltas using system dynamics modelling: rice agriculture in the Mekong Delta's An Giang Province, Vietnam. Sci Total Environ 559:326-338

Cote M, Nightingale AJ (2012) Resilience thinking meets social theory: situating social change in socio-ecological systems (SES) research. Prog Hum Geogr 36(4):475-489

Cosenz F (2014) A dynamic viewpoint to design performance management systems in academic institutions: theory and practice. Int $\mathbf{J}$ Public Adm 37(13):955-969

Cretney R (2014) Resilience for whom? Emerging critical geographies of socio-ecological resilience. Geogr Compass 8(9):627-640
Davoudi S, Shaw K, Haider LJ, Quinlan AE, Peterson GD, Wilkinson $C$ et al (2012) Resilience: a bridging concept or a dead end? "Reframing" resilience: challenges. Plan Theory Pract 13(2):299-333

Davoudi S, Brooks E, Mehmood A (2013) Evolutionary resilience and strategies for climate adaptation. Plan Pract Res 28(3):307-322

Duit A (2015) Resilience thinking: lessons for public administration. Public Adm 94(2):364-380

Feofilovs M, Gravelsins A, Pagano AJ, Romagnoli F (2019) Increasing resilience of the natural gas system with implementation of renewable methane in the context of Latvia: a system dynamics model. Energy Procedia 158:3944-3950

Folke C (2006) Resilience: the emergence of a perspective for social-ecological systems and analyses. Glob Environ Change 16(3):253-267

Gallopín GC (2006) Linkages between vulnerability, resilience, and adaptive capacity. Glob Environ Change 16(3):293-303

Givens JE, Padowski J, Guzman CD, Malek K, Witinok-Huber R, Cosens B, Adam J (2018) Incorporating social system dynamics in the columbia river basin: food-energy-water resilience and sustainability modeling in the Yakima River Basin. Front Environ Sci 6:104

Glandon DM (2015) Measuring resilience is not enough; we must apply the research. Researchers and practitioners need a common language to make this happen. Ecol Soc 20(2):27

Gray SA, Gray S, De Kok JL, Helfgott AE, O'Dwyer B, Jordan R, Nyaki A (2015) Using fuzzy cognitive mapping as a participatory approach to analyze change, preferred states, and perceived resilience of social-ecological systems. Ecol Soc. https://doi. org/10.5751/ES-07396-200211

Ha TM, Duong VH (2018) Using system dynamics modelling and communication strategies for a resilient and smart city in Vietnam. Int J Environ Sci Sustain Dev 3(1):10-16

Hawes C, Reed C (2006) Theoretical steps towards modelling resilience in complex systems. Lecture notes in computer science (including subseries lecture notes in artificial intelligence and lecture notes in bioinformatics), 3980 LNCS, pp 644-653. https ://doi.org/10.1007/11751540_68

Henly-Shepard S, Gray SA, Cox LJ (2015) The use of participatory modeling to promote social learning and facilitate community disaster planning. Environ Sci Policy 45:109-122

Herrera H (2017) Resilience for whom? The problem structuring process of the resilience analysis. Sustainability 9(7):1196

Herrera H (2018) Public policy design for climate change adaptation: a dynamic performance management approach to enhance resilience. In: Borgonovi E, Anessi-Pessina E, Bianchi C (eds) Outcome-based performance management in the public sector system. Dynamics for performance management. Springer, Cham, pp 425-445

Holling CS, Gunderson LH (2002) Panarchy: understanding transformations in human and natural systems. Island Press, Washington, DC

Joakim EP, Mortsch L, Oulahen G, Harford D, Klein Y, Damude K, Tang K (2016) Using system dynamics to model social vulnerability and resilience to coastal hazards. Int J Emerg Manage 12(4):366-391

Khanmohammadi S, Farahmand H, Kashani H (2018) A system dynamics approach to the seismic resilience enhancement of hospitals. Int J Disaster Risk Reduct 31:220-233

König HJ, Sghaier M, Schuler J, Abdeladhim M, Helming K, Tonneau JP et al (2012) Participatory impact assessment of soil and water conservation scenarios in Oum Zessar watershed, Tunisia. Environ Manag 50(1):153-165

Lane DC (2008) The emergence and use of diagramming in system dynamics: a critical account. Syst Res Behav Sci 25(1):3-23 
Machado CP, Morandi MIW, Sellitto M (2019) System dynamics and learning scenarios for process improvement and regional resilience: a study in the Footwear Industry of Southern Brazil. Systemic Practice and Action Research 32:663-686

Mahmoud M, Liu Y, Hartmann H, Stewart S, Wagener T, Semmens D et al (2009) A formal framework for scenario development in support of environmental decision-making. Environ Model Softw 24(7):798-808

Mitchell M, Lockwood M, Moore SA, Clement S (2015) Scenario analysis for biodiversity conservation: a social-ecological system approach in the Australian Alps. J Environ Manage 150:69-80

Randers J (1980) Guidelines for model conceptualization. Elements of the system dynamics method. MIT Press, Cambridge, pp $117-139$

Resilience Alliance (2010) Assessing resilience in social-ecological systems: workbook for practitioners. Version 2.0. https://www. resalliance.org/3871.php

Richardson GP (2011) Reflections on the foundations of system dynamics. Syst Dyn Rev 27(3):219-243

SESAN (2015) Plan hambre cero en el corredor seco. Gobierno de Guatemala, Guatemala

Sterman JD (2000) Business dynamics. Irwin/McGraw-Hill, Boston

Swart RJ, Raskin P, Robinson J (2004) The problem of the future: sustainability science and scenario analysis. Glob Environ Change 14(2):137-146

Tompkins EL, Adger WN (2004) Does adaptive management of natural resources enhance resilience to climate change? Ecol Soc 9(2):10
Vhurumuku E (2014) Food security indicators, Nairobi

Walker BH, Salt D (2012) Resilience practice: building capacity to absorb disturbance and maintain function. Island Press, Washington, DC

Walker B, Carpenter S, Anderies J, Abel N, Cumming G, Janssen M et al (2002) Resilience management in social-ecological systems: a working hypothesis for a participatory approach. Conserv Ecol $6(1): 14$

Walker B, Holling CS, Carpenter SR, Kinzig A (2004) Resilience, adaptability and transformability in social-ecological systems. Ecol Soc 9(2):5

You SJ, Ham EK, Lee J, Cho DG, Chon JH (2017) Design strategies to enhance resilience of ecosystem services in urban wetland-using system thinking. J Korea Soc Environ Restor Technol 20(4):43-61

Zagonel AA (2002) Model conceptualization in group model building: a review of the literature exploring the tension between representing reality and negotiating a social order. In: Proceedings of the 20th international system dynamics conference, vol 51, pp. $170-182$

Zagonel AA (2004) Reflecting on group model building used to support welfare reform in New York state. SUNY, Albany

Publisher's Note Springer Nature remains neutral with regard to jurisdictional claims in published maps and institutional affiliations. 